\title{
Cylindrically confined assembly of diblock copolymer under oscillatory shear flow
}

\author{
Y.-Q. Guo, J.-X. Pan, J.-J. Zhang, M.-N. Sun, B.-F. Wang, H.-Sh. Wu \\ School of Chemistry and Materials Science, Shanxi Normal University, Linfen, 041004, China
}

Received November 30, 2015, in final form January 18, 2016

\begin{abstract}
Manipulating the self-assembly nanostructures with combined different control measures is emerging as a promising route for numerous applications to generate templates and scaffolds for nanostructured materials. Here, the two different control measures are a cylindrical confinement and an oscillatory shear flow. We study the phase behavior of diblock copolymer confined in nanopore under oscillatory shear by considering different $D / L_{0}$ ( $D$ is the diameter of the cylindrical nanopore, $L_{0}$ is the domain spacing) and different shears via Cell Dynamics Simulation. Under different $D / L_{0}$, in the system occurs different morphology evolution and phase transition with the changing of amplitude and frequency. Meanwhile, it forms a series of novel morphologies. For each $D / L_{0}$, we construct a phase diagram of different forms and analyze the reason why the phase transition occurs. We find that although the morphologies are different under different $D / L_{0}$, the reason of the phase transition with the changing of amplitude and frequency is roughly the same, all caused by the interplay of the field effect and confinement effect. These results can guide an experimentalist to an easy method of creating the ordered, defect-free nanostructured materials using a combination of the cylindrical confinement and oscillatory shear flow.
\end{abstract}

Key words: self-assembly, block copolymer, cylindrical confinement, oscillatory shear flow

PACS: $64.75 . Y z, 64.75 . V a, 83.80 . U v, 83.10 . T v$

\section{Introduction}

Block copolymer is a class of soft material capable of self-assembling to form ordered structures at nanometer scales. These structures possess a potential for various applications to nanotechnologies such as lithographic templates for nanowires, photonic crystals, high-density magnetic storage media, drug delivery and biomineralization. So, the self-assembly of block copolymer has attracted much interest as an efficient and effective means to create structures at nanometer scales. Obviously, how to manipulate these self-assembled nanostructures have become the key of the research, so understanding the controlling factors is an intriguing field of research that holds promise for further expanding the nanofabrication. In general, the control measures mainly include a confined environment [1] 2], imposed external field [3 4], substrate induction [5, 6], doping [7] 8], and branched molecular architectures [9] etc. Thereinto, confinement effect makes the polymer system form a series of novel morphologies that are not accessible in the bulk, and the external effect makes the structures more ordered. They both provide an effective route to manipulate the self-assembled nanostructures.

During the past years, the effects of a confined environment have been extensively explored based on a large number of experimental and theoretical studies. The internal branching is one of the confinements, i.e., one imposes some restrictions on the conformational freedom. For example, Ilnytskyi et al. analyzed the peculiarities of the equilibrium morphologies observed for the star and comb diblock polymers with equal molecular mass but with the differences in both intramolecular architecture and composition fraction [9]. In addition, the geometrical confinement can be classified as one-, two-, and three-dimensionally confined systems. The one-dimensionally confined system [10 11] is the simplest case, and its research is very mature. For a more complex three-dimensionally confined system, the studies are relatively few so far [12 13]. The research area of two-dimensional confinement is developing 
rapidly. When placing the block copolymer in a cylindrical pore, a series of novel morphologies that were not accessible in the bulk or in the one-dimensionally confined systems were observed at different degrees of confinement $D / L_{0}$. Russell and co-workers discovered that the lamellae-, cylinder-, and sphere-forming block copolymer of polystyrene- $b$-polybutadiene (PS- $b$-PBD) were confined in the pores of anodized aluminumoxide (AAO) membranes experimentally [14-18]. They find that under cylindrical confinement, block copolymer formed various kinds of novel structures that were not accessible in the bulk, such as stacked disks, concentric cylinders, torus-like structure, core-shell structure, single row and zigzag arrangement of spherical microdomains, single-, double-, triple-helical structures etc. Sun et al. also observed the diameter-dependence of morphology confined within the ordered porous alumina templates, but the block copolymer that they used was polystyrene- $b$-poly (methyl methacrylate) (PS-b-PMMA) [19] and polyethylene-co-butylene- $b$-polyethylene oxide (PHB-b-PEO) experimentally [20]. For symmetric lamellae-forming diblock copolymer in cylindrical pores, many novel morphologies were predicted based on dynamic density functional theory (DDFT) [21]-23], Monte Carlo (MC) [24] 25], selfconsistent field theory (SCFT) [26], and simulated annealing technique (SAT) [27]. For the asymmetric cylinder-forming diblock copolymer, the structures in the cylindrical pores severely deviated from the bulk. The novel structures of spontaneous formation, such as stacked toroids, single helix, double helix and perforated tubes, were observed by means of a SAT [28 29] and SCFT [30,32]. For the asymmetric sphere-forming diblock copolymer, the study of it was rare. Pinna et al. predicted tremendous rich morphologies of sphere-forming diblock copolymer in cylindrical nanopores by using the cell dynamics simulation (CDS) [33]. Recently, the phase behavior of sphere-forming triblock copolymer confined in nanopores was investigated by Hao et al. by means of a DDFT [34]. They observed that typical structures were different from the bulk morphologies, which were consistent with the available experiments.

As concerns the imposition of an external field, this is a versatile control measure to obtain the longrange order and then to create microstructures with potential applications in biomaterials, optics, and microelectronics. Earlier, during the study of block copolymer there were observed various alignments in a lamellar block copolymer by using TEM and SAXS. Thereinto, polystyrene-polyisoprene is the most representative. The parallel and perpendicular orientations were observed by K.I. Winey and S.S. Patel et al. in 1993 [35] and 1995 [36], respectively; the transverse orientation was found by V.K. Gupta et al. [37] and Y.M. Zhang [38. Then, B.S. Pinheiro and K.I. Winey observed the mixed parallel-perpendicular morphologies in diblock copolymer systems at intermediate temperatures [39]. Afterwards, researchers theoretically predicted the phase transition of the lamellar [40,43], ring [44], hexagonal cylinders [45] diblock copolymer subjected to shear flow further. These predictions were proved by researchers with various numerical simulation methods, such as CDS [46] 49], nonequilibrium molecular dynamics simulation (NEMD) [50, 51], dissipative particle dynamics method (DPD) [52 53], SCFT and lattice Boltzmann (LB) method [54], Brownian dynamics (BD) [55], mean-field approach (MFA) [56], density functional theory (DFT) [57, 58], MC [59] etc. For all these cases, shear flow plays an important role as a means for aligning the microscopic domains.

As we all know, the polymer system can form all kinds of novel structures that are different from the bulk morphologies under cylindrical confinement and form ordered structures under shear flow. So, we wonder what the phase behavior of polymer system is under both these two control measures, and it should be interesting when these two control measures affect the system. Previously, Pinna et al. [60] combined the two control measures of the one-dimension confinement and steady shear flow. They demonstrated the shear alignment and the shear-induced transitions in sphere-forming diblock copolymer single layer and bilayer films by cell dynamics simulation that was observed experimentally by Hong et al. [61], and for the first time presented a nontrivial alignment mechanism of a single layer of spherical domains in shear. On this basis, we dedicate ourselves to investigate the phase behavior of diblock copolymer within cylindrical pores under oscillatory shear flow by means of the CDS of time dependent Ginzbrug-Landau (TDGL) theory proposed by Oono and co-workers [62,66]. It will further provide some guiding function for experimentalists. The other parts of this paper are organized as follows: section 2 is devoted to the description of the model and simulation method; section 3 is the numerical results and discussions; and finally, section 4 gives a brief conclusion in this work. 


\section{Models and simulation methods}

Our simulations are performed in a neutral cylindrical nanopore with a diameter $D$ and a length $L_{z}$. We employ a TDGL approach in the form of the CDS, which is a very fast computational technique. For $A B$ diblock copolymer, the structure can be described by an order parameter $\phi(\mathbf{r}, t)=\phi_{\mathrm{A}}-\phi_{\mathrm{B}}+(1-2 f)$, where $\phi_{\mathrm{A}}$ and $\phi_{\mathrm{B}}$ are the local volume fractions of $\mathrm{A}$ and $\mathrm{B}$ monomers, respectively. The fraction of A monomers in a diblock copolymer chain is denoted by $f, f=N_{\mathrm{A}} /\left(N_{\mathrm{A}}+N_{\mathrm{B}}\right)$. The kinetics and morphological evolution are described, in the spirit of linear irreversible thermodynamics, by the TDGL equation for a diffusive field coupled with an external velocity field, which can be written as [67]

$$
\frac{\partial \phi(\mathbf{r}, t)}{\partial t}+\mathbf{v} \cdot \nabla \phi(\mathbf{r}, t)=M \nabla^{2}\left\{\frac{\delta F[\phi(\mathbf{r}, t)]}{\delta \phi(\mathbf{r}, t)}\right\}
$$

where $M$ is a phenomenological mobility constant and is set to $1 . \mathbf{r}$ is an external velocity field.

For simplicity, we set the shear rate as

$$
v(\mathbf{r}, t)=(0,0, \gamma \omega y \cos (\omega t)),
$$

where $\gamma$ is amplitude, and $\omega$ is frequency. We set $z$-axis (the direction of the arrows) is the shear direction.

Here, we use a two-order-parameter model in [68 69]. The long-range part $F_{\mathrm{L}}$ and the short-range part $F_{\mathrm{S}}$ are given by

$$
F_{\mathrm{L}}=\frac{\alpha}{2} \iint \mathrm{d} \mathbf{r} \mathrm{d} \mathbf{r}^{\prime} G\left(\mathbf{r}, \mathbf{r}^{\prime}\right)\left[\phi(\mathbf{r})-\phi_{0}\right]\left[\phi(\mathbf{r})-\phi_{0}\right]
$$

and

$$
F_{S}=\iint \mathrm{d} \mathbf{r}\left\{f(\phi)+\frac{D}{2}[\nabla \phi(\mathbf{r})]^{2}\right\}
$$

respectively. The long-range part is relatively simple, in which $G\left(\mathbf{r}, \mathbf{r}^{\prime}\right)$ is the Green's function defined by the equation $-\nabla^{2} G\left(\mathbf{r}, \mathbf{r}^{\prime}\right)=\delta\left(\mathbf{r}-\mathbf{r}^{\prime}\right)$, while $\alpha$ is a parameter that introduces a chain-length dependence to the free-energy, $\phi_{0}$ is the spatial averages of $\phi$, we should set $\phi_{0}=0$ in the case of symmetric copolymers. As for the short-range part, $D$ is a positive constant that plays the role of a diffusion coefficient, and $f(\phi)=-A \tanh (\phi)+\phi$. We carry out computer simulations of the model system by using the CDS proposed by Oono and Puri [62 66]. In three-dimensional CDS, the system is discretized on a $L_{x} \times L_{y} \times L_{z}$ cubic lattice, and the order parameter for each cell is defined as $\phi(\mathbf{n}, t)$, where $\mathbf{n}=\left(n_{x}, n_{y}, n_{z}\right)$ is the lattice position and $n_{x}, n_{y}$, and $n_{z}$ are integers between 1 and $L$. The Laplacian in CDS is approximated by

$$
\nabla^{2} \phi(\mathbf{n})=\langle\langle\phi(\mathbf{n})\rangle\rangle-\phi(\mathbf{n}),
$$

where $\langle\langle\phi(\mathbf{n})\rangle\rangle$ represents the following summation of $\phi(\mathbf{n})$ for the nearest neighbors (n.), the nextnearest neighbors (n.n.), and the next-next-nearest neighbors (n.n.n.) [66]

$$
\langle\langle\phi(\mathbf{n})\rangle\rangle=\frac{6}{80} \sum_{\mathbf{n}=\text { n. }} \phi(\mathbf{r})+\frac{3}{80} \sum_{\mathbf{n}=\text { n.n. }} \phi(\mathbf{r})+\frac{1}{80} \sum_{\mathbf{n}=\text { n.n.n. }} \phi(\mathbf{r}) .
$$

In our simulations, we set $\Delta x, \Delta y, \Delta z$ are 1 , and $\Delta t=1.0$. Then, equation (2.1) can be transformed into the following difference equation:

$$
\phi(\mathbf{r}, t+\Delta t)=\phi(\mathbf{r}, t)-\frac{1}{2} \gamma \sin (\omega t) y t[\phi(x, y, z+1, t)-\phi(x, y, z-1, t)]+M\left(\left\langle\left\langle I_{\phi}\right\rangle\right\rangle-I_{\phi}\right)-\alpha \phi(\mathbf{r}, t)
$$

with

$$
I_{\phi}=-D(\langle\langle\phi\rangle\rangle-\phi)-A \tanh (\phi)+\phi .
$$

We have chosen $z$-axis as the flow direction, $y$-axis as the velocity gradient direction and $x$-axis as the vorticity axis. In addition to Dirichlet boundary condition [33], a shear periodic boundary condition proposed by Ohta et al. [70,72] has been applied to $z$ direction along the pore. With the shear strain $\Upsilon$, this boundary condition is written as

$$
\phi\left(n_{x}, n_{y}, n_{z}, t\right)=\phi\left(n_{x}+N_{x} L, n_{y}+N_{y} L, n_{z}+N_{y} L+\Upsilon(t) N_{y} L\right),
$$

where $N_{x}, N_{y}$, and $N_{z}$ are arbitrary integers. All parameters in this paper are scaled, and all of them are dimensionless [62]. 


\section{Numerical results and discussion}

In order to simulate the confined self-assembly of $\mathrm{AB}$ diblock copolymer under oscillatory shear flow, we construct the cylindrical nanopore of diameter $D$ in cubic lattice. The volume is $V=L_{x} \times L_{y} \times L_{z}$ with $L_{x}=L_{y}=D+m$ and $L_{\text {pore }}=L_{z}$, where $m=2$ when $D$ is odd and $m=3$ when $D$ is even. Polymers cannot occupy the wall sites which are the lattice sites outside the cylinder with diameter $D$ and the wall is impenetrable. The extra $m$ in $L_{x}$ and $L_{y}$ ensures that each site inside the cylindrical pore can find its nearest neighbor, the next-nearest neighbor, and the next-next-nearest neighbor cells. These sites are either inside the pore or in the wall. Thus, the polymers are confined in the cylindrical nanopore of diameter $D$. In this paper, we investigate the phase behavior under oscillatory shear of diblock copolymer in the cylindrical pore with different $D / L_{0}$, which $L_{0}$ is the domain spacing, refer to [32].

Firstly, we investigate the effect of oscillatory shear flow in cylindrical nanopore of $D / L_{0}=1.01$, $L_{\text {pore }} / L_{0}=8.1$. It is noted that the oscillatory shear is imposed on the disordered structures rather than the final self-assembled structures. With the simulation on the continuous variation of shear amplitude and shear frequency, we roughly construct a structure diagram in figure 1 In figure 1 symbol • represents single-helical structure that is abbreviated as SH, $\star$ represents half-cylinder structure that is abbreviated as HC. The half-cylinder refers to A phase occupying half of the cylinder along the pipe axis.

In figure 1 the amplitude, $\gamma$, varies from 0 to 1.0, and the frequency, $\omega$, varies from 0 to 0.1 . We can clearly see that in small amplitudes, such as $\gamma \leqslant 0.15$, the field effect is too weak to have a sufficient capability to affect the morphology, therefore, no phase transition is observed at the given frequency, and the single-helical structure is always preserved. Typical snapshots of this case are shown in figures 2(a)-(d). Moreover, in the small frequencies $\omega \leqslant 0.02$, the structure is single-helical at all amplitudes. At amplitudes $0.2<\gamma<0.35$, with an increasing frequency, the single-helical structure transforms to the halfcylinder, and then reverses to the single-helical structure. At the larger amplitude, when we increase the frequency, the phase transition occurs more than once. In addition to the phase transition from the singlehelical structure to half-cylinder, and then to the single-helical structure, the phase morphology turns to half-cylinder finally, as shown in figures 2(e)-(h). Furthermore, we also observe that the morphology turns directly to the half-cylinder from the single-helical structure with an increasing amplitude at the frequency 0.09. At some frequencies, such as $0.07 \leqslant \omega \leqslant 0.08$, while increasing the amplitude, the phase transition occurs from single-helical structure to half-cylinder, then reverses to a single-helical structure,

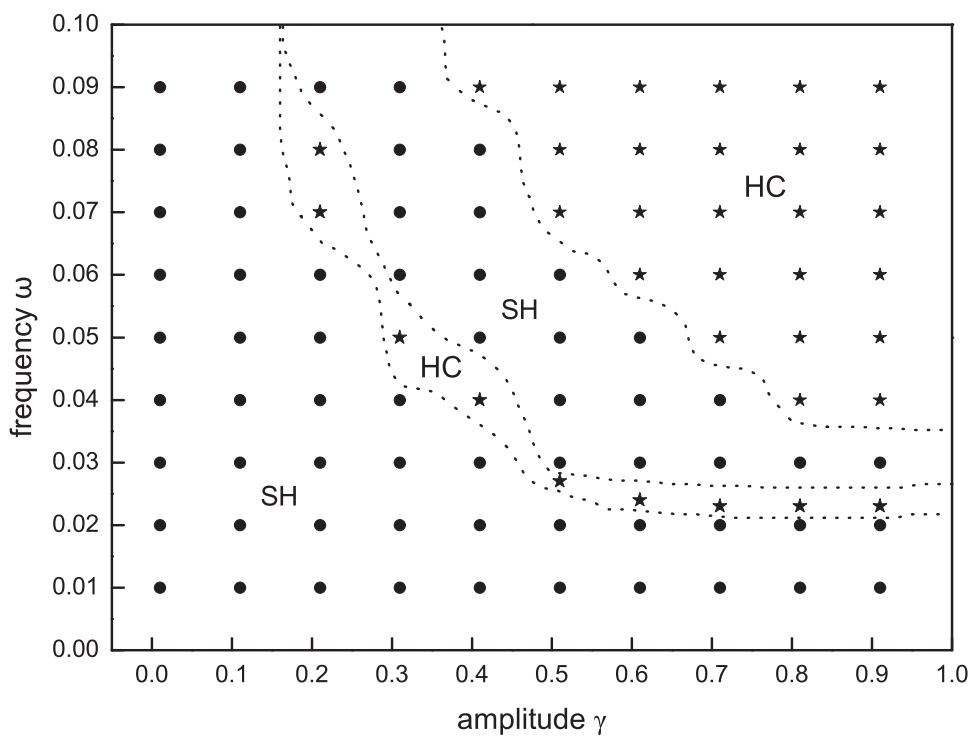

Figure 1. Phase diagram of the diblock copolymer in nanopore $D / L_{0}=1.01$ under oscillatory shear at different amplitudes $\gamma$ and frequencies $\omega$. • represents single-helical structure which is abbreviated as $\mathrm{SH} ; \star$ represents half-cylinder structure which is abbreviated as HC. 


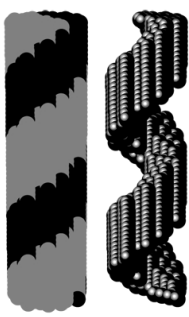

(a)

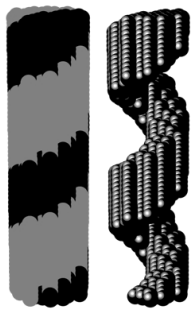

(e)

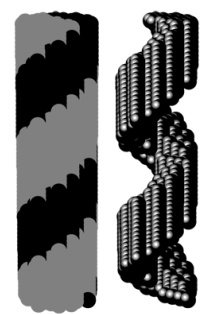

(b)

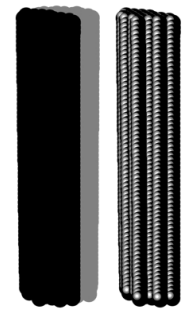

(f)

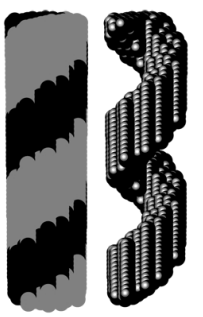

(c)

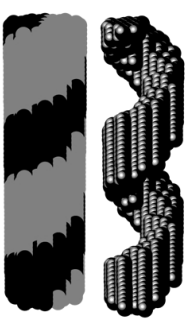

(g)

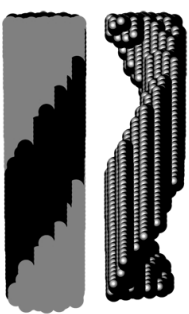

(d)

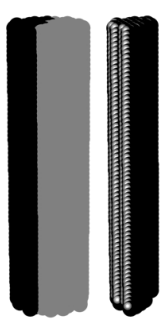

(h)

Figure 2. Pattern evolution of diblock copolymer in nanopore of $D / L_{0}=1.01$ under different oscillatory shears: (a) $\gamma=0.01, \omega=0.00001$, (b) $\gamma=0.01, \omega=0.001$, (c) $\gamma=0.01, \omega=0.1$, (d) $\gamma=0.01, \omega=1.0$; (e) $\gamma=$ $0.41, \omega=0.03$, (f) $\gamma=0.41, \omega=0.04$, (g) $\gamma=0.41, \omega=0.05$, (h) $\gamma=0.41, \omega=0.09$. Phase A is represented by the black regions, phase $\mathrm{B}$ by the gray regions.

and then transforms to a half-cylinder structure. On the whole, the single-helical structure mainly concentrates on the region of the weak oscillatory shear flow, which can be seen in the bottom left-hand corner in figure 1. the half-cylinder structure mainly concentrates on the region of the strong oscillatory shear flow, which can be seen in the top right-hand corner in figure 1. Moreover, the critical shear frequency of the phase transition becomes smaller and smaller with an increasing amplitude.

As seen in figure 2 mentioned before, it shows the morphology evolution with an increasing frequency at two typical amplitudes, $\gamma=0.01$ and $\gamma=0.41$. Phase A is represented by black regions, phase B by gray regions. In figures 2(a)-(d), no phase transition occurs during the frequency and in figures 2(e)-(h), the phase transition occurs more than once. These results are mainly due to the interplay of two factors: the field effect caused by the oscillatory shear flow and the confinement effect produced by the confinement boundary. Meanwhile, the field effect is the combined effect of both amplitude and frequency. For the single-helical structure in the bottom left-hand corner, it is the same as the structure that is confined in the cylinder with no shear of the same diameter, which is in agreement with the previous studies by Morita [73] and Pinna [33]. They found that the helical structure was usually observed at incommensurate conditions. In our simulation, the length and diameter are slightly incommensurable with the domain spacing; the amplitude and frequency are relatively low, the field effect is weaker while the confinement effect is dominant. Thus, similarly, the single-helical structure is due to the extensional forces when the length, diameter and the lamellae spacing are not commensurate. For the half-cylinder structure in the top right-hand corner, the amplitude and frequency are higher. Relatively speaking, the field effect plays an important role, so we get the half-cylinder structure along the direction of oscillatory shear flow. For the repeated phase transition with an increasing frequency at a certain amplitude in figures 2 (e)-(h), we consider that the coupling of amplitude and frequency plays a certain role. Compared with the field effect, the confinement effect has an absolute superiority when the frequency is weaker. It is easier to form a single-helical structure [figure 2 (e)]. With increasing the frequency, the movement of segments A and B strengthens along the oscillatory shear direction, the coarse graining process is also intensified along the field direction and then the ordered half-cylinder structure is formed [figure 2(f)]. With a further increase of the frequency, the movement is faster, more and more A and B segments accumulate, they push each other and then it formes a single-helical structure again [figure 2 (g)], and the nature of this 


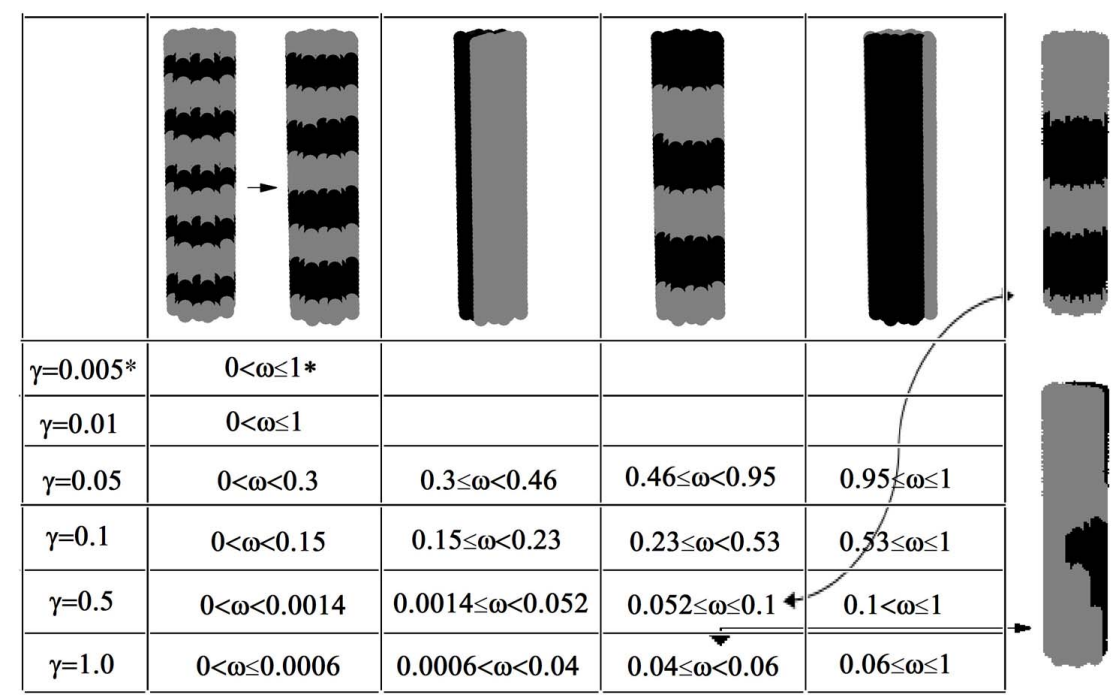

Figure 3. Simulation snapshots of the diblock copolymer in nanopore $D / L_{0}=0.76$ under oscillatory shear at different amplitudes $\gamma$ and frequencies $\omega$. Phase A is represented by the black regions, phase B by the gray regions.

structure is different from the helical under a weaker shear. When the frequency is high enough, the field effect plays a leading role, it forms the ordered half-cylinder structure along the pipe axis [figure 2(h)].

Then, we concentrate on the phase behavior under oscillatory shear flow in cylindrical nanopore of $D / L_{0}=0.76$ and $L_{\text {pore }} / L_{0}=8.1$. The simulation snapshots under oscillatory shear flow at different amplitudes $\gamma$ and frequencies $\omega$ are shown in figure 3 As we can see in figure 3 we control the frequency between 0 and 1, and consider the amplitude of various stages. Overall, it preferentially adopts a piledpancakes structure when the shear is low; while it adopts a half-cylinder structure that is parallel to the pipe axis when the shear is high. When $\gamma=0.005$ and $\gamma=0.01$, the domain structure remains the piledpancakes in the entire frequency range. However, the number of pancakes decreases with an increase of frequency when the amplitude $\gamma$ is 0.01 , at the same time, the layer spacing becomes wider. $*$ represents the morphology and has no change, and it is used to distinguish these two different cases. When $\gamma=$ 0.05 and $\gamma=0.1$, with an increasing frequency, the piled-pancakes structure evolves into half-cylinder structure due to the aggravation of the coarse graining process along the pipe axis. At the further increase of frequency, at the coupling of amplitude and frequency, the system transforms to the piled-pancakes structure and the number of pancakes decreases. Undoubtedly, then it turns to the half-cylinder structure when the shear is strong. It is certain that the critical shear frequency of phase transition and frequency range of each structure are different from each other. This phenomenon also exists in $\gamma=0.5$ and $\gamma=1.0$. The higher the amplitude is, the lower the critical shear frequency is. The frequency range in the same structure is smaller when the amplitude is higher, just like the piled-pancaked in $0<\omega<0.0014, \gamma=0.5$ and $0<\omega \leqslant 0.0006, \gamma=1.0$; and the half-cylinder in $0.0014 \leqslant \omega<0.052, \gamma=0.5$ and $0.0006<\omega<0.04$, $\gamma=1.0$. Also, the number of pancakes that formed again are less than before, as well, the layer spacing is wider than before in $\gamma=0.5$. However, it forms a mixed structure between piled-pancakes and halfcylinder just in a small range (i.e., $0.04 \leqslant \omega<0.06$ ) under $\gamma=1.0$. This is chiefly because at $\gamma=1.0$, the vibration amplitude along the pipe axis is large, it is difficult to stack and easy to stretch along the field direction. Certainly, in the end of the frequency range, the system turns to a stable half-cylinder structure of paralleling to the pipe axis.

Similar to the reason of the phenomenon in nanopore of $D / L_{0}=1.01$, it is the result of the combination of the confinement effect and field effect. At a smaller amplitude, no phase transition mainly depends on the confinement effect. However, the phase transition at a larger amplitude is mainly decided by the size of the frequency. The slower the frequency is, the weaker the field effect is. Thus, it is easier to form piled-pancakes structure, as well as the structure with no shear, which is in agreement with the study 
by Pinna [33], as a result of the competition between the effect of the neutral surface and the effect of incommensurability. When the shear is weaker, the surface effect prevails at a small diameter, while above a certain diameter, the bulk effect takes over. The first phase transition to the half-cylinder with an increase of the frequency is due to the intensified graining process along the pipe axis caused by the strong oscillation of A and B segments. In case of a further increase of the frequency, these segments would be more piled up in $z$-axis and jostle each other to form the piled-pancakes structure due to the too fast vibration. The last phase transition is caused by a strong field effect, and the half-cylinder structure is obtained so that A phase and B phase are completely separated. Furthermore, the decrease of the critical frequency with an increase of amplitude also indicates that the phase transition occurs only if the amplitude and frequency intercouple with each other.

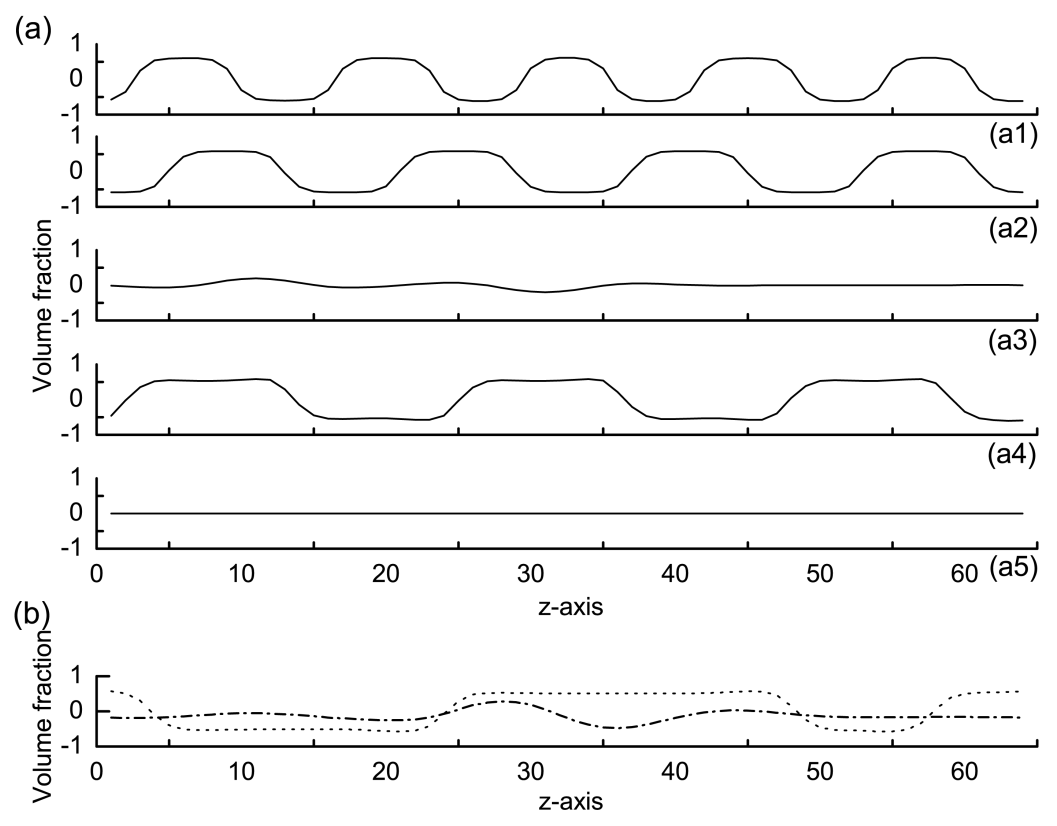

Figure 4. The order-parameter profiles of $\phi$ along the pipe axis under different oscillatory shears. (a) $\gamma=$ 0.1 , from top to bottom, the frequencies are $\omega=0.0001,0.04,0.15,0.25,1.0$, respectively. (b) The dotted line represents $\gamma=0.5, \omega=0.052$; the dash-dotted line represents $\gamma=1.0, \omega=0.04$.

In figure 4 the above mentioned phase transition can be clearly seen in a different way. It displays the order-parameter profiles of $\phi$ along the pipe axis under different oscillatory shears. As seen in figure 4 (a), $\gamma=0.1$, from (a1) to (a5), the frequencies are $\omega=0.0001,0.04,0.15,0.25,1.0$, respectively. $\phi>0$ represents A-rich domain, $\phi<0$ represents B-rich domain. This indicates that if the profile of $\phi$ along $z$-axis has convexities and concavities, the convexity represents A phase, while the concavity represents B phase. From figures 4 (a1) to (a2), the number of convexities decreases from 5 to 4 with an increase of frequency from 0.0001 to 0.04 which corresponds to the domain morphologies in figure 3 An approximate straight line in figure 4 (a3) represents $\phi \approx 0$, it means that A and B phases are uniformly distributed in the $z$-axis. Thus, the approximate straight line corresponds to the half-cylinder structure in $0.15 \leqslant \omega<0.23, \gamma=0.1$ as shown in figure 3 Then, the profile of $\phi$ along the $z$-axis changes from a straight line [figure 4 (a3)] to a curved line [figure 4 (a4)], and then to a perfect straight line [figure 4(a5)] with an increase of frequency from 0.15 to 1.0. It means that the half-cylinder structure caused by the field effect is more perfect than that caused by the intensity coarse graining process. In figure 4 (b), the dotted line represents the orderparameter profile of $\gamma=0.5, \omega=0.052$, and the dash-dotted line represents the order-parameter profile of $\gamma=1.0, \omega=0.04$. As we can see, they are completely consistent with the structures that an arrow points to in figure 3

For a relatively large nanopore with $D / L_{0}=4.05$ and $L_{\text {pore }} / L_{0}=8.1$, the phase diagrams of top view under different oscillatory shears are shown in figure 5. The characteristic morphologies are found 


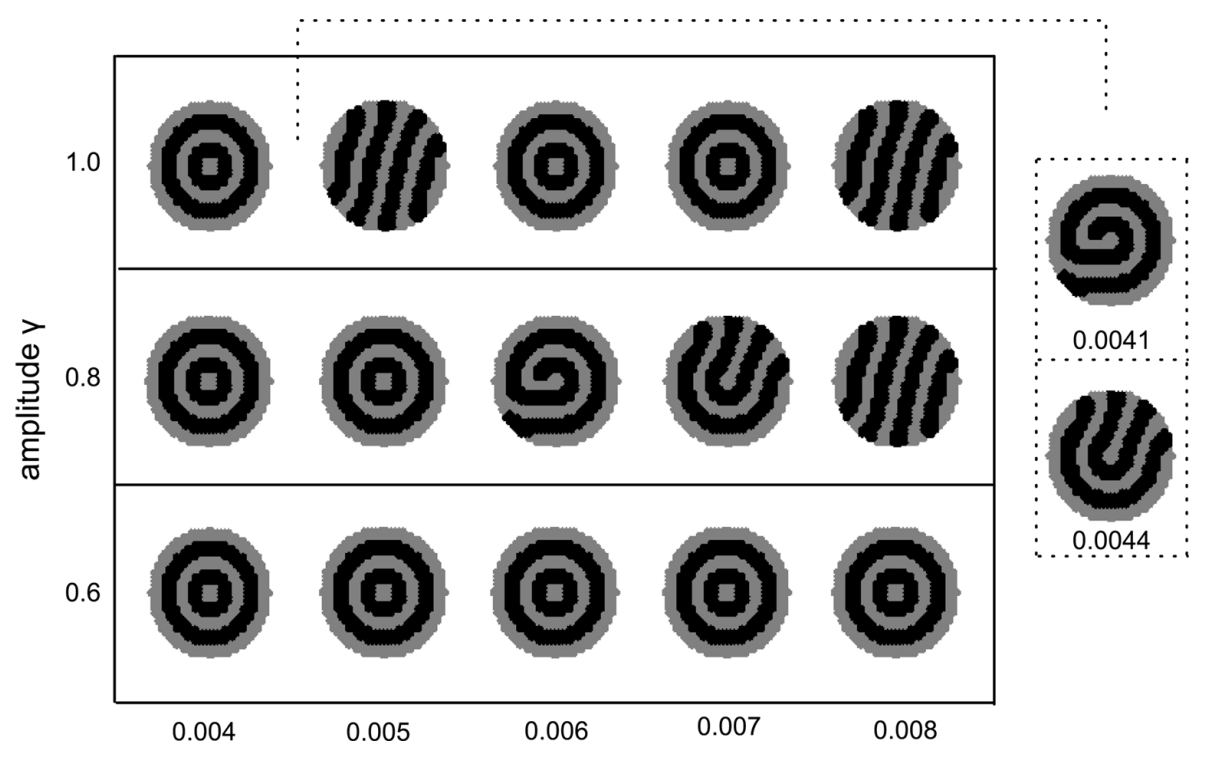

Figure 5. The top view phase diagrams of diblock copolymer in nanopore of $D / L_{0}=4.05$ under different oscillatory shears. Phase A is represented by the black regions, phase B by the gray regions.

mainly in the small frequency range of $0.004 \leqslant \omega \leqslant 0.008$ in $0.6 \leqslant \gamma \leqslant 1.0$. In general, the most interesting thing is the big response caused by a small effect, figure 5 is just this kind of situation. As we have seen, when $\gamma=1.0$, phase transition occurs repeatedly in a very small frequency range. The transformation occurs from the initial concentric ring structure to the parallel lamellar structure, then the concentric ring comes into being once again, and then transforms to the parallel lamellae with an increase of frequency. Thereinto, there exists an intermediate state in the process of turning to the parallel lamellae for the first time, it is the "Swiss roll" and "horseshoe" structures in $\omega=0.0041$ and $\omega=0.0044$, respectively. At intermediate amplitude, $\gamma=0.8$, since the amplitude is not enough large, the phase transition only

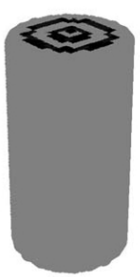

(a)

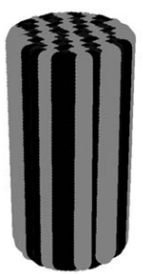

(d)

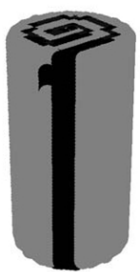

(b)

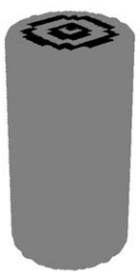

(e)

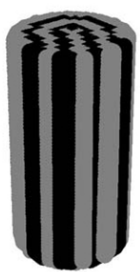

(c)

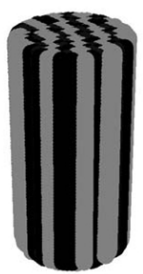

(f)

Figure 6. Pattern evolution of diblock copolymer in nanopore of $D / L_{0}=4.05$ under different oscillatory shears: $\gamma=1.0$, (a) $\omega=0.004$, (b) $\omega=0.0041$, (c) $\omega=0.0044$, (d) $\omega=0.005$, (e) $\omega=0.006$, (f) $\omega=0.008$. 
occurs from the concentric ring to the parallel lamellae. Certainly, the intermediate state (i.e., the "Swiss roll" and "horseshoe" structures) also exist. However, when the amplitude decreases to 0.6, we can find that all the structures are a concentric ring in the given frequency range. Due to the amplitude being relatively small, even if the frequency increases to 0.008 , the field effect is still weaker than the confinement effect.

As seen in figure 6 it shows the morphologies of full view that corresponds to $\gamma=1.0$ in figure 5 The three-dimensional morphology evolution with an increase of the frequency in figure 6 gives us a better visual perception than that in figure 6. As for the reason why this phase transition occurs, we can also interpret it as the interplay of the field effect caused by the oscillatory shear and the confinement effect produced by the confinement boundary. The concentric ring structure is formed under this large nanopore with no shear, and the same as the structure of the weaker shears, because the field effect is almost neglected. When the shear is strong, the field effect prevails, then it forms the parallel lamellae along the shear axis. The phase transition in the given frequency range is mainly induced by the amplitude and frequency intercoupling with each other as before.

\section{Conclusions}

In the present work, we have combined two different control measures of the cylindrical confinement and oscillatory shear flow to manipulate the self-assembly nanostructures and obtained novel morphologies. Specifically, we have predicted the phase behavior of diblock copolymer confined in nanopore under oscillatory shear by considering the different $D / L_{0}$ and different shears. We have found that in nanopore of $D / L_{0}=1.01$, when the amplitude is small, there is no phase transition observed at a given frequency; while at a certain amplitude, the system undergoes a phase transition from single-helical structure to half-cylinder, and then reverses to a single-helical structure, transforms to half-cylinder structure with an increase of shear frequency, finally. When we put the diblock copolymer in nanopore of $D / L_{0}=0.76$, the situation is similar, except that the structure of single-helical structure is replaced by piled-pancakes. When the diblock copolymer is placed in a large nanopore of $D / L_{0}=4.05$, similarly, no phase transition is observed at a smaller amplitude, and the phase transition occurs with an increase of the frequency under a relatively bigger amplitude. It changes from a concentric ring to the parallel lamellar structure, then reverses to a concentric ring, and finally, turns to a parallel lamellar structure. However, in the process of phase transition, there exist two transient states, they are the "Swiss roll" and "horseshoe" structures. We have discussed the transformation of three kinds of typical structures and constructed a phase diagram of different forms with the changing amplitude and frequency. Although the morphologies at different $D / L_{0}$ are different, the reason for the phase transition with the change of amplitude and frequency is roughly the same, which is the interplay of the field effect caused by the oscillatory shear and the confinement effect produced by the confinement boundary. These results can provide an easy method to create the ordered, defect-free nanostructured materials for an experimentalist through the combined control measures of the cylindrical confinement and oscillatory shear flow.

\section{Acknowledgements}

Project supported by the National Natural Science Foundation of China (Grant No. 21373131), the Specialized Research Fund for the Doctoral Program of Higher Education of China (Grant No. 20121404110004), and the Provincial Natural Science Foundation of Shanxi (Grant No. 2015011004), the Research Foundation for Excellent Talents of Shanxi Provincial Department of Human Resources and Social Security. 


\section{References}

1. Lee D., Kim M.Y., Bae D., Jeon G., Kim M., Kwak J., Park S.J., Kim J.U., Kim J.K., Macromolecules, 2014, 47, 3997; doi $10.1021 / \mathrm{ma} 500761 \mathrm{e}$

2. Jiang W.B., Lang W.C., Li S.B., Wang X.H., Chin. J. Chem. Phys., 2014, 27, 337; doi $10.1063 / 1674-0068 / 27 / 03 / 337-342$.

3. Nikoubashman A., Davis R.L., Michal B.T., Chaikin P.M., Register R.A., Panagiotopoulos A.Z., ACS Nano, 2014, 8, 8015; doi 10.1021/nn502068e.

4. Nikoubashman A., Register R.A., Panagiotopoulos A.Z., Soft Matter, 2013, 9, 9960; doi 10.1039/c3sm51759d

5. Chen P., Liang H.J., Xia R., Qian J.S., Feng X.S., Macromolecules, 2013, 46, 922; doi 10.1021/ma301203a

6. Kim S.O., Solak H.H., Stoykovich M.P., Ferrier N.J., Pablo J.J., Nealey P.F., Nature, 2003, 424, 411; doi $10.1038 /$ nature01775

7. Yan L.T., Xie X.M., Prog. Polym. Sci., 2013, 38, 369; doi 10.1016/j.progpolymsci.2012.05.001

8. Akcora P., Liu H.J., Kumar S.K., Moll J., Li Y., Benicewicz B.C., Schadler L.S., Acehan D., Panagiotopoulos A.Z., Pryamitsyn V., Ganesan V., Llavsky J., Thiyagarajan P., Colby R.H., Douglas J.F., Nat. Mater., 2009, 8, 354; doi 10.1038/NMAT2404

9. Ilnytskyi J.M., Patsahan T., Holovko M., Krouskop P.E., Makowski M.P., Macromolecules, 2008, 41, 9904; doi $10.1021 / \mathrm{ma} 801045 \mathrm{z}$

10. Wu X.S., Chen P., Feng X.S., Xia R., Qian J.S., Soft Matter, 2013, 9, 5909; doi 10.1039/c3sm50169h

11. Pan J.X., Zhang J.J., Wang B.F., Wu H.S., Sun M.N., Chinese Phys. B, 2013, 22, 026401; doi $10.1088 / 1674-1056 / 22 / 2 / 026401$

12. Pinna M., Hiltl S., Guo X.H., Boker A., Zvelindovsky A.V., ACS Nano, 2010, 4, 2845; doi 10.1021/nn901853e

13. Fan H.L., Jin Z.X., Macromolecules, 2014, 47, 2674; doi 10.1021/ma500123g

14. Xiang H.Q., Shin K., Kim T., Moon S.I., McCarthy T.J., Russell T.P., Macromolecules, 2004, 37, 5660; doi $10.1021 / \mathrm{ma} 049299 \mathrm{~m}$

15. Shin K., Xiang H.Q., Moon S.I., Kim T., McCarthy T.J., Russell T.P., Science, 2004, 306, 76; doi $10.1126 /$ science.1100090

16. Xiang H.Q., Shin K., Kim T., Moon S.I., McCarthy T.J., Russell T.P., Macromolecules, 2005, 38, 1055; doi $10.1021 / \mathrm{ma} 0476036$.

17. Xiang H.Q., Shin K., Kim T., Moon S.I., McCarthy T.J., Russell T.P., J. Polym. Sci. B Polym. Phys., 2005, 43, 3377; doi 10.1002/polb.20641

18. Dobriyal P., Xiang H.Q., Kazuyuki M., Chen J.T., Jinnai H., Russell T.P., Macromolecules, 2009, 42, 9082; doi 10.1021/ma901730a

19. Sun Y., Steinhart M., Zschech D., Adhikari R., Michler G.H., Gosele U., Macromol. Rapid Commun., 2005, 26, 369; doi $10.1002 /$ marc. 200400545

20. Thomas A., Schierhorn M., Wu Y.Y., Stucky G., J. Mater. Chem., 2007, 17, 4558; doi 10.1039/b702895d

21. Knoll A., Lyakhova K.S., Horvat A., Krausch G., Sevink G.J.A., Zvelindovsky A.V., Magerle R., Nat. Mater., 2004, 3, 886; doi $10.1038 /$ nmat1258

22. Sevink G.J.A., Zvelindovsky A.V., Fraaije J.G.E.M., Huinink H.P., J. Chem. Phys., 2001, 115, 8226; doi $10.1063 / 1.1403437$

23. Sevink G.J.A., Zvelindovsky A.V., J. Chem. Phys., 2008, 128, 084901; doi 10.1063/1.2829406

24. He X.H., Song M., Liang H.J., Pan C.Y., J. Chem. Phys., 2001, 114, 10510; doi 10.1063/1.1372189

25. Wang Q., J. Chem. Phys., 2007, 126, 024903; doi 10.1063/1.2406078.

26. Li W.H., Wickham R.A., Macromolecules, 2009, 42, 7530; doi $10.1021 / \mathrm{ma} 900667 \mathrm{w}$

27. Yu B., Sun P.C., Chen T.H., Jin Q.H., Ding D.T., Li B.H., Shi A.C., J. Chem. Phys., 2007, 127, 114906; doi $10.1063 / 1.2768920$

28. Yu B., Sun P.C., Chen T.H., Jin Q.H., Ding D.T., Li B.H., Shi A.C., Phys. Rev. Lett., 2006, 96, 138306; doi 10.1103/PhysRevLett.96.138306.

29. Yu B., Jin Q.H., Ding D.T., Li B.H., Shi A.C., Macromolecules, 2008, 41, 4042; doi 10.1021/ma702430v

30. Chen P., Liang H.J., Shi A.C., Macromolecules, 2007, 40, 7329; doi 10.1021/ma0705164

31. Li W.H., Wickham R.A., Macromolecules, 2006, 39, 8492; doi 10.1021/ma061630+

32. Wu Y.Y., Cheng G.S., Katsov K., Sides S.W., Wang J.F., Tang J., Fredrickson G.H., Moskovits M., Studky G.D., Nat. Mater., 2004, 3, 816; doi 10.1038/nmat1230

33. Pinna M., Guo X.H., Zvelindovsky A.V., J. Chem. Phys., 2009, 131, 214902; doi $10.1063 / 1.3264946$

34. Hao Q.H., Miao B., Song Q.G., Niu X.H., Liu T.J., Polymer, 2014, 55, 4281; doi 10.1016/j.polymer.2014.06.062

35. Winey K.I., Patel S.S., Larson R.G., Watanabe H., Macromolecules, 1993, 26, 2542; doi 10.1021/ma00062a024

36. Patel S.S., Larson R.G., Winey K.I., Watanabe H., Macromolecules, 1995, 28, 4313; doi $10.1021 / \mathrm{ma} 00116 a 038$ 
37. Gupta V.K., Krishnamoorti R., Kornfield J.A., Smith S.D., Macromolecules, 1995, 28, 4464; doi $10.1021 / \mathrm{ma} 00117 \mathrm{a} 015$

38. Zhang Y.M., Wiesner U., J. Chem. Phys., 1995, 103, 4784; doi 10.1063/1.470613.

39. Pinheiro B.S., Winey K.I., Macromolecules, 1998, 31, 4447; doi 10.1021/ma980186a

40. Gupta V.K., Krishnamoorti R., Chen Z.R., Kornfield J.A., Smith S.D., Satkowski M.M., Grothaus J.T., Macromolecules, 1996, 29, 875; doi $10.1021 /$ ma950925c

41. Wang H., Kesani P.K., Balsara N.P., Hammouda B., Macromolecules, 1997, 30, 982; doi $10.1021 / \mathrm{ma} 961269 \mathrm{z}$

42. Morozov A.N., Zvelindovsky A.V., Fraaije J.G.E.M., Phys. Rev. E, 2001, 64, 051803; doi 10.1103/PhysRevE.64.051803

43. Chen P., Vinals J., Macromolecules, 2002, 35, 4183; doi 10.1021/ma011586s

44. Morozov A.N., Fraaije J.G.E.M., Macromolecules, 2001, 34, 1526; doi 10.1021/ma001564q

45. Morozov A.N., Zvelindovsky A.V., Fraaije J.G.E.M., Phys. Rev. E, 2000, 61, 4125; doi 10.1103/PhysRevE.61.4125

46. Pinna M., Zvelindovsky A.V., Soft Matter, 2008, 4, 316; doi 10.1039/B706815H

47. Pinna M., Zvelindovsky A.V., J. Chem. Phys., 2006, 125, 154905; doi 10.1063/1.2356468

48. Rychkov I., Macromol. Theory Simul., 2005, 14, 207; doi 10.1002/mats.200400023

49. Guo Y.Q., Zhang J.J., Wang B.F., Wu H.S., Sun M.N., Pan J.X., Condens. Matter Phys., 2015, 18, 23801; doi 10.5488/CMP.18.23801

50. Guo H.X., J. Chem. Phys., 2006, 125, 214902; doi 10.1063/1.2400232

51. Guo H.X., Kremer K., J. Chem. Phys., 2007, 127, 054902; doi:10.1063/1.2752158

52. You L.Y., Chen L.J., Qian H.J., Lu Z.Y., Macromolecules, 2007, 40, 5222; doi 10.1021/ma0703103

53. Liu W., Qian H.J., Li Z.S., Sun C.C., Phys. Rev. E, 2006, 74, 021802; doi 10.1103/PhysRevE.74.021802.

54. Cui J., Ma Z.W., Li W., Jiang W., Chem. Phys., 2011, 386, 81; doi 10.1016/j.chemphys.2011.06.012

55. Peters B.L., Hernandez A.R., Pike D.Q., Müller M., Pablo J.J., Macromolecules, 2012, 45, 8109; doi $10.1021 / \mathrm{ma} 301541 \mathrm{f}$

56. Fredrickson G.H., J. Rheol., 1994, 38, 1045; doi 10.1122/1.550584

57. Zvelindovsky A.V., Sevink G.J., Europhys. Lett., 2003, 62, 370; doi 10.1209/epl/i2003-00406-6

58. Zvelindovsky A.V., Sevink G.J.A., Vlimmeren B.A.C., Maurits N.M., Fraaije J.G.E.M., Phys. Rev. E, 1998, 57, R4879; doi 10.1103/PhysRevE.57.R4879

59. Ji S., Ding J.D., J. Chem. Phys., 2005, 122, 164901; doi 10.1063/1.1884595

60. Pinna M., Zvelindovsky A.V.M., Guo X.H., Stokes C.L., Soft Matter, 2011, 7, 6991; doi 10.1039/C1SM05478C

61. Hong Y.R., Adamson D.H., Chaikin P.M., Register R.A., Soft Matter, 2009, 5, 1687; doi 10.1039/B820312A

62. Oono Y., Puri S., Phys. Rev. Lett., 1987, 58, 836; doi 10.1103/PhysRevLett.58.836

63. Oono Y., Puri S., Phys. Rev. A, 1988, 38, 434; doi 10.1103/PhysRevA.38.434

64. Puri S., Oono Y., Phys. Rev. A, 1988, 38, 1542; doi 10.1103/PhysRevA.38.1542

65. Shinozaki A., Oono Y., Phys. Rev. A, 1992, 45, R2161; doi 10.1103/PhysRevA.45.R2161

66. Shinozaki A., Oono Y., Phys. Rev. E, 1993, 48, 2622; doi 10.1103/PhysRevE.48.2622

67. Ohta T., Nozaki H., Doi M., J. Chem. Phys., 1990, 93, 2664; doi 10.1063/1.458905

68. Komura S., Kodama H., Phys. Rev. E, 1997, 55, 1722; doi 10.1103/PhysRevE.55.1722

69. Roan J., Shakhnovich E.I., Phys. Rev. E, 1999, 59, 2109; doi 10.1103/PhysRevE.59.2109

70. Chen D., Doi M., J. Chem. Phys., 1989, 91, 2656; doi 10.1063/1.456975

71. Doi M., Chen D., J. Chem. Phys., 1989, 90, 5271; doi 10.1063/1.456430

72. Ohta T., Enomoto Y., Harden J.L., Doi M., Macromolecules, 1993, 26, 4928; doi 10.1021/ma00070a029

73. Morita H., Kawakatsu T., Doi M., Yamaguchi D., Takenaka M., Hashimoto T., J. Phys. Soc. Jpn., 2004, 73, 1371; doi 10.1143/JPSJ.73.1371 


\title{
Циліндрично обмежене скупчення діблочного кополімера під дією осциляційного зсувного потоку
}

\author{
Ю.-К. Гуо, Ю.-К. Пен, Дж.-Дж. Жанг, М.-Н. Сун, В.-Ф. Вонг, Х.-Ш. Ву \\ Школа хімії та матеріалознавства, Шанхайський нормальний університет, Лінфен, 041004, Китай
}

\begin{abstract}
Керування самоскупченими наноструктурами з допомогою поєднання різних заходів керування виявляється багатообіцяючим шляхом для чисельних застосувань для генерування шаблонів для наноструктурованих матеріалів. У цій статті двома різними заходами керування $\epsilon$ циліндричне обмеження та осциляційний зсувний потік. Досліджується фазова поведінка діблочного кополімера, обмеженого нанопорою під дією осциляційного зсуву з врахуванням різних $D / L_{0}\left(D-\right.$ це діаметр циліндричної пори, $L_{0}-$ це розмір домена) та різних зсувів з допомогою симуляцій коміркової динаміки. При різних $D / L_{0}$, в системі відбувається еволюція різної морфології і фазовий перехід зі зміною амплітуди і частоти. Тим часом, утворюється ряд нових морфологій. Для кожного $D / L_{0}$, ми будуємо фазову діаграму різних форм та аналізуємо причини здійснення фазового переходу. Встановлено, що, хоча морфології відрізняються при різних $D / L_{0}$, причина фазового переходу при зміні амплітуди і частоти $\epsilon$ приблизно однаковою, а саме вона полягає в поєднанні польового ефекту і ефекту просторового обмеження. Ці результати можуть дати експериментаторам простий метод створення впорядкованих, бездефектних наноструктурованих матеріалів за рахунок поєднання циліндричного обмеження та осциляційного зсувного потоку.
\end{abstract}

Ключові слова: самоскупчення, блочний кополімер, циліндричне обмеження, осциляційний зсувний потік 